\title{
EVALUATION OF THE SUITABILITY OF IONIC LIQUID- BASED LIQUID-LIQUID MICROEXTRACTIONS FOR BLOOD PROTEIN REMOVAL
}

\section{$\underline{\text { AUTHORS }}$}

Marieke De Boeck ${ }^{\mathrm{a}}$, Lien Moreels ${ }^{\mathrm{a}}$, Wim Dehaen $^{\mathrm{b}}$, Jan Tytgat $^{\mathrm{a}}$, Eva Cuypers ${ }^{\mathrm{a}}$

a Toxicology and Pharmacology, Department of Pharmaceutical and Pharmacological Sciences, University of Leuven (KU Leuven), Campus Gasthuisberg, O\&N II, P.O. Box 922, Herestraat 49, 3000 Leuven, Belgium

${ }^{b}$ Molecular Design and Synthesis, Department of Chemistry, University of Leuven (KU Leuven), Campus Arenberg, P.O. Box 2404, Celestijnenlaan 200F, 3001 Leuven, Belgium

ORCID: $\quad$ Marieke De Boeck 0000-0001-7910-7465

Lien Moreels 0000-0002-7173-7195

Wim Dehaen 0000-0002-9597-0629

Eva Cuypers $\quad$ 0000-0002-6411-2461

\section{CORRESPONDING AUTHOR}

Prof. Dr. Eva Cuypers

Toxicology and Pharmacology

Department of Pharmaceutical and Pharmacological Sciences

University of Leuven (KU Leuven)

Campus Gasthuisberg, O\&N II

Herestraat 49 - P.O. Box 922

3000 Leuven

BELGIUM

Tel: $\quad+3216323403$

Fax: + 3216323405

Email: eva.cuypers@kuleuven.be 


\section{$1 \quad$ ABSTRACT}

2 The analysis of biological samples, such as whole blood, comes with several sample preparation challenges. Biological matrices often contain a variety of endogenous components that can interfere with the determination of xenobiotics. Especially blood plasma proteins (e.g. serum albumin) are known to interfere with electrospray ionization and result in analyte ion suppression. Sample preparation techniques should guarantee adequate removal of these biomolecules. The current study aims to determine to which extent proteins are removed from whole blood samples, using ionic liquid-based dispersive liquid-liquid microextraction (ILDLLME). A qualitative comparison of the protein presence in extracts of IL-DLLME, solidphase extraction (SPE) and protein precipitation (PP) was performed, using sodium dodecyl sulfate polyacrylamide gel electrophoresis (SDS-PAGE). Additionally, UV/VIS spectrophotometry was used to determine the protein content of a whole blood sample and ILDLLME, SPE and PP extracts of the same sample. Finally, a quantitative comparison of matrix effects of benzodiazepines present in both whole blood and water samples. SDS-PAGE results showed that IL-DLLME extracts still contained proteins (i.e. albumin, hemoglobin); however, band intensities were comparable to SPE extracts. Spectrophotometric tests showed a total protein content of approximately $2 \mathrm{mg} / \mathrm{mL}$ in the final extracts. PP showed the highest protein extraction rate $(19 \mathrm{mg} / \mathrm{mL})$. Quantitative ME results showed no significant differences $(\alpha=$ 0.05) between blood and water IL-DLLME extracts. Overall, this is the first study to conclude that IL-DLLME is able to sufficiently remove blood proteins from whole blood samples, in order to avoid significant ion suppression.

\section{KEYWORDS}

Ionic liquid; Liquid-liquid microextraction; Blood protein removal; SDS-PAGE; Matrix effect; LC-MS/MS

ACN: acetonitrile; BSA: bovine serum albumin; CV: coefficient of variation; IL: ionic liquid; ILDLLME: ionic liquid-based dispersive liquid-liquid microextraction; ME: matrix effect; $\mathrm{MeOH}$ : methanol; PP: protein precipitation; SDS-PAGE: sodium dodecyl sulfate polyacrylamide gel electrophoresis; SPE: solid-phase extraction; Tris-HCl: tris(hydroxymethyl)aminomethane hydrochloride; TSIL: task-specific ionic liquid; VOS: volatile organic solvent. 
Alternative solvents are introduced in sample preparation as a result of the increasing awareness of volatile organic solvent (VOS) shortcomings. High flammability, high volatility and low selectivity make VOSs less attractive solvents when compared to ionic liquids (ILs). ILs are liquid salts with melting points below $100{ }^{\circ} \mathrm{C}$. They have a negligible volatility, low flammability and good thermal stability [1,2]. Moreover, anions and cations can be easily tuned by adding diverse functional groups, which results in task-specific ionic liquids (TSILs) [3]. All these advantages make ILs important new extraction solvents in sample preparation. To date, they are studied and applied in several microextraction procedures [4]. Especially the use of hydrophobic ILs, such as imidazolium-based ILs, has been reported for the extraction of metal ions and organic compounds in aqueous samples [5]. An important aspect of the further implementation of ILs in analytical chemistry is their application for drug analysis in biological samples.

In toxicology, biological samples are the most important source of information. Especially blood is a frequently analyzed sample matrix for the quantification of legal and illegal drugs [6]. There are several challenges associated with the analysis of biological samples, since they contain endogenous interferences that can hamper accurate quantification, such as proteins, lipids and sugars [7]. Proteins are probably the most abundant source of endogenous biomolecules in blood, more specifically, serum albumin. Average albumin blood concentrations are estimated at $35-52 \mathrm{mg} / \mathrm{mL}$ [8]. Average total protein concentrations, that primarily consist of albumin and globulins, are estimated at $65-85 \mathrm{mg} / \mathrm{mL}$ in adults [9]. Moreover, if red blood cells in whole blood samples are ruptured, the elevated concentration of free hemoglobin can form additional challenges, as these concentrations can reach up to 160 $\mathrm{mg} / \mathrm{mL}$ [10]. It is important to eliminate proteins from biological samples prior to analysis, since high protein concentrations can co-elute with the analyte, using liquid chromatographyelectrospray ionization-tandem mass spectrometry (LC-ESI-MS/MS) and can drastically affect the ionization process [7]. These so-called matrix effects (MEs) can have a negative impact on method accuracy and precision, and - in case of ion suppression - can result in a decreased sensitivity. Furthermore, the presence of proteins can hamper the extraction of drugs from complex sample matrices, as a result of protein-drug binding interactions [11]. To overcome the mentioned problems, it is necessary to implement an adequate sample clean-up step in the analytical process. Established bioanalytical sample preparation techniques are protein 
1 precipitation (PP), solid-phase extraction (SPE) and liquid-liquid extraction (LLE). PP is a fast and easy alternative; however, it has the lowest matrix removal capacity [12]. Contrarily, SPE is considered a superior sample clean-up method, even so, it is less attractive due to complex and tedious procedures. Furthermore, reproducibility problems and cartridge blockage limit the application of SPE $[13,14]$.

Since the introduction of ILs as solvents in liquid-liquid microextraction protocols, several studies have demonstrated their applicability for the extraction of biological samples, such as blood, urine, saliva, etc. [15]. However, little research has been performed on the ability of hydrophobic ILs to remove biological matrix components. The presence of these endogenous substances, such as proteins, can be a potential concern since ILs have been described to extract biomolecules. In 2005, Wang et al. demonstrated the ability of hydrophobic imidazolium-based ILs to extract amino acids [16]. These ILs are typically used in liquid-liquid sample preparation protocols and therefore can result in the undesired extraction of protein and thus matrix effects. On the other hand, it should be noted that larger proteins generally have a lower IL solubility. The main mechanisms of protein partitioning into the IL layer in two-phase systems relies on electrostatic and hydrophobic interactions [5].

The present work focusses on the determination of proteins in IL-based dispersive liquid-liquid micro-extracts (IL-DLLME). Sodium dodecyl sulfate polyacrylamide gel electrophoresis (SDS-PAGE) was performed to compare serum protein presence in IL-DLLME, protein precipitation (PP) and solid-phase extraction (SPE) extracts. This qualitative test provides insight into the protein removal capacity of the mentioned sample preparation techniques. A semi-quantitative comparison was performed based on the measured protein content of whole blood samples, compared to IL-DLLME, SPE and PP whole blood extracts. Protein contents were determined using ultraviolet/visible (UV/VIS) spectrophotometry. Finally, quantitative ME tests were performed for the analysis of benzodiazepines in both whole blood and Milli-Q water IL-DLLME extracts. A comparison of both extracts provides information on the influence of whole blood matrix components on the ionization of benzodiazepines using LC-ESI-MS/MS.

\section{MATERIALS AND METHODS}

\subsection{CHEMICALS AND REAGENTS}

Solvents used for sample preparation were obtained from Merck (Darmstadt, Germany): acetic acid, acetone, chloroform, ethyl acetate, methanol $(\mathrm{MeOH})$ and potassium 
1 dihydrogenphosphate. 1-Butyl-3-methylimidazolium hexafluorophosphate (BMIm $\mathrm{PF}_{6}, 99.5$ $\%$ ), was purchased from IOLITEC Ionic Liquids Technologies GmbH (Heilbronn, Germany). Acetonitrile (ACN) was obtained from Biosolve (Valkenswaard, The Netherlands).

The following substances were purchased to prepare SDS-PAGE running buffer and sample buffer: tris(hydroxymethyl)aminomethane hydrochloride (Tris- $\mathrm{HCl}$ ), Coomassie Brilliant Blue R250 and hydrogen chloride were obtained from Merck (Darmstadt, Germany). Glycerol and dithiothreitol were obtained from Sigma Aldrich (Steinheim, Germany). SDS was obtained from Boehringer (Ingelheim am Rhein, Germany). Tricine and SimplyBlue ${ }^{\mathrm{TM}}$ SafeStain were purchased from Thermo Fisher Scientific (Massachusetts, USA). Water was purified using a Milli-Q Water Purification System (Millipore, Brussels, Belgium). Tris (1 M)-Tricine (1 M)SDS ( $1 \% \mathrm{v} / \mathrm{v}$ ) aqueous running buffer ( $\mathrm{pH} 8.3$ ) was prepared by dissolving $121.1 \mathrm{~g}$ Tris- $\mathrm{HCl}$ and $179.2 \mathrm{~g}$ Tricine in $800 \mathrm{~mL}$ Milli-Q water. $\mathrm{pH}$ was adjusted to 8.3 with hydrogen chloride, followed by the addition of $50 \mathrm{~mL}$ SDS $20 \%$ solution. The buffer was diluted to $1 \mathrm{~L}$ with Milli$\mathrm{Q}$ water. Before use, the running buffer was diluted 1/10 v/v in Milli-Q water. Tricine sample buffer (0.1 M, pH 6.8) was prepared by diluting $5 \mathrm{~mL}$ of Tris $\mathrm{HCl}(1 \mathrm{M}, \mathrm{pH} 6.8), 12 \mathrm{~mL}$ glycerol, $4 \mathrm{~g}$ SDS, $1.55 \mathrm{~g}$ dithiothreitol and $10 \mathrm{mg}$ Coomassie Blue R250 to $50 \mathrm{~mL}$ with MilliQ water. Furthermore, as a positive control, bovine serum albumin (BSA) (10 mg/mL) was purchased from New England Biolabs (Massachusetts, USA). PageRuler low range unstained protein ladder (3.4 to $100 \mathrm{kDa}$ ) was purchased from Thermo Fisher Scientific (Massachusetts).

To perform ME tests, the following methanolic benzodiazepine reference standards (1.0 $\mathrm{mg} / \mathrm{mL}$ ) were purchased: alprazolam, clobazam, clonazepam, diazepam, flurazepam, lorazepam, lormetazepam, midazolam, nitrazepam, nordiazepam, oxazepam, prazepam, temazepam and zopiclone from Cerilliant (Round Rock, Texas, USA). 7-aminoflunitrazepam, bromazepam, chlordiazepoxide, estazolam, etizolam, flunitrazepam, triazolam and zolpidem tartrate were purchased from LGC (Molsheim, France). Powder reference standards of brotizolam, ethyl loflazepate and loprazolam mesilate were obtained from EDQM Council of Europe (Strasbourg, France), Sanofi-Aventis (Diegem, Belgium) and the British Pharmacopoeia Commission Laboratory (Teddington, UK), respectively. All powder standards were dissolved in $\mathrm{MeOH}$ to obtain a final concentration of $1.0 \mathrm{mg} / \mathrm{mL}$. Clorazepate, clotiazepam and cloxazolam were extracted from their commercially available tablets, respectively, Tranxene ${ }^{\circledR}$, Clozan $^{\circledR}$ and Akton ${ }^{\circledR}$. Extracts were diluted to a final concentration of $1.0 \mathrm{mg} / \mathrm{mL}$ in $\mathrm{MeOH}$. A benzodiazepine stock solution was prepared by mixing all reference 
compounds to a final concentration of $1.67 \mu \mathrm{g} / \mathrm{mL}$ in $\mathrm{MeOH}$. Stock solutions were stored at $20{ }^{\circ} \mathrm{C}$. All mobile phase solvents and additives were LC-MS grade quality. $\mathrm{MeOH}$ and ACN were obtained from Biosolve (Valkenswaard, The Netherlands). Ammonium hydroxide and ammonium bicarbonate were purchased from Sigma-Aldrich (Bornem, Belgium).

\subsection{BIOLOGICAL SAMPLES}

Blank whole blood samples were obtained from Blood Transfusion Centre Leuven (Gasthuisberg, Leuven, Belgium). The Committee for Medical Ethics (UZ Leuven, Belgium) permitted the use of whole blood. To all blood samples, $1 \%$ sodium fluoride was added and they were stored at $-20{ }^{\circ} \mathrm{C}$. Before use, samples were screened for the presence of benzodiazepines, using a validated SPE-LC-MS/MS method [17].

\subsection{SDS-PAGE}

The IL-DLLME protocol for benzodiazepine extraction, described by De Boeck et al. [18], was used for SDS-PAGE sample preparation. $1 \mathrm{~mL}$ of blank whole blood was extracted using 60 $\mu \mathrm{L}$ of BMIm $\mathrm{PF}_{6}$. After separation of the aqueous and IL layer, $6 \mu \mathrm{L}$ IL was collected and mixed with $6 \mu \mathrm{L}$ tricine sample buffer $(0.1 \mathrm{M}, \mathrm{pH}$ 6.8). The used SPE protocol was thoroughly described by Verplaetse et al. [17]. The extraction was performed starting from $1 \mathrm{~mL}$ blank whole blood. The final eluted extract was evaporated to dryness using a vacuum concentrator. The residue was dissolved in $60 \mu \mathrm{L}$ Milli-Q water. Finally, $6 \mu \mathrm{L}$ of this solution was mixed with $6 \mu \mathrm{L}$ tricine sample buffer $(0.1 \mathrm{M}, \mathrm{pH}$ 6.8). The used PP protocol consisted in adding 2 $\mathrm{mL}$ ACN to $1 \mathrm{~mL}$ blank whole blood. The supernatant was collected and evaporated to dryness. The residue was dissolved in $60 \mu \mathrm{L}$ Milli-Q water. Six $\mu \mathrm{L}$ of the solution was mixed with $6 \mu \mathrm{L}$ tricine sample buffer $(0.1 \mathrm{M}, \mathrm{pH}$ 6.8). As a positive control, $2 \mu \mathrm{L}$ of the BSA standard was added to $10 \mu \mathrm{L}$ SDS sample buffer.

IL-DLLME, SPE, PP and BSA samples were heated for 2 min at $80{ }^{\circ} \mathrm{C}$ to ensure denaturation of proteins. Twelve $\mu \mathrm{L}$ of each sample and the protein ladder was loaded onto a Novex ${ }^{\mathrm{TM}} 16 \%$ Tricine Protein Mini Gel (1.0 mm, 12-well) (Thermo Fisher Scientific, Massachusetts, USA). Gel electrophoresis was performed for $1.5 \mathrm{~h}$ at $125 \mathrm{~V}$, using a Xcell SureLock ${ }^{\mathrm{TM}}$ Mini-cell system (Thermo Fisher Scientific, Massachusetts, USA). Finally, the gel was stained following the SimplyBlue ${ }^{\mathrm{TM}}$ SafeStain protocol. 


\subsection{UV/VIS SPECTROPHOTOMETRY}

Whole blood samples ( $\mathrm{n}=3$ donors) were compared to their respective IL-DLLME, SPE and PP extracts, based on protein content. Three $\mu \mathrm{L}$ of each sample was measured $(n=5)$ using a NanoDrop ND-1000 UV/VIS spectrophotometer (Isogen Life Sciences, De Meern, The Netherlands) at a wavelength that is strongly absorbed by proteins; $280 \mathrm{~nm}$. Protein concentrations were automatically calculated by the NanoDrop Software version 3.1.2, based on the linear relationship between protein absorbance and concentration. As a blank measurement, Milli-Q water was measured prior to each sample.

The used IL-DLLME procedure was described in full detail by De Boeck et al. [18]. One mL of blank whole blood was extracted using $60 \mu \mathrm{L}$ of $\mathrm{BMIm} \mathrm{PF}_{6}$. Subsequently, three $\mu \mathrm{L}$ of the collected IL was analyzed. The used SPE protocol was described by Verplaetse et al. [17]. The extraction was performed starting from $1 \mathrm{~mL}$ blank whole blood. The final eluted extract was evaporated to dryness using a vacuum concentrator and the residue was dissolved in $60 \mu \mathrm{L}$ Milli-Q water. Three $\mu \mathrm{L}$ of the final solution was analyzed. The used PP protocol consisted in adding $2 \mathrm{~mL}$ ACN to $1 \mathrm{~mL}$ blank whole blood. The supernatant was collected and evaporated to dryness. The residue was dissolved in $60 \mu \mathrm{L}$ Milli-Q water and three $\mu \mathrm{L}$ of the final solution was analyzed. Next to the extracts, the initial whole blood samples were analyzed. Prior to analysis, the whole blood samples were diluted 1/20 (v/v) in Milli-Q water in order to obtain a measurable liquid.

\subsection{LC-ESI-MS/MS: MATRIX EFFECT}

A Shimadzu Prominence Ultra-Fast Liquid Chromatograph XR System (Shimadzu Benelux, Jette, Belgium) equipped with a Kinetex ${ }^{\circledR}$ Biphenyl LC Column $(100 \mathrm{~mm} \times 2.1 \mathrm{~mm}, 2.6 \mu \mathrm{m}$ particle size) (Phenomenex, Utrecht, The Netherlands) was used. The LC system was coupled to a 3200 QTRAP mass spectrometer (Sciex, Halle, Belgium), operated in scheduled multiple reaction monitoring (sMRM) scan mode.

For a detailed description of the used IL-DLLME-LC-MS/MS method for benzodiazepine analysis, the reader is referred to the published work of De Boeck et al. [18]. The IL-DLLME preparation was performed in triplicate on two sets of samples: blank whole blood and blank Milli-Q water. The samples were post-extraction spiked at $167 \mathrm{ng} / \mathrm{mL}$ with benzodiazepine standard stock solution and analyzed using LC-ESI-MS/MS. The post-extraction spiked samples were compared to a pure benzodiazepine standard in $\mathrm{MeOH}$, at the same concentration. 
ME values were calculated as follows [19]:

$$
M E=\frac{A U C_{\text {post-extraction spiked sample }}}{A U C_{\text {standard in methanol }}} .100
$$

ME values were calculated for both sample sets (whole blood and Milli-Q water extracts) and compared by means of a multiple $t$-test analysis $(\alpha=0.05)$. Significantly lower ME values for whole blood extracts would indicate that interfering blood matrix components were not sufficiently removed using IL-DLLME. Additionally, coefficients of variation (CVs) $(\mathrm{n}=3)$ were calculated and the acceptance limit was $\leq 15 \%$.

\section{RESULTS AND DISCUSSION}

\subsection{SDS-PAGE}

Figure 1 shows gel electrophoresis results of IL-DLLME, SPE, PP and BSA samples. The BSA sample shows a broad band at its molecular mass of $66 \mathrm{kDa}$. The same albumin band was observed in IL-DLLME, PP and SPE sample extracts. It should be noted that the band could also be a result of inadequate hemoglobin removal, since its molecular weight is comparable to albumin, i.e. $64 \mathrm{kDa}$. However, the chance of finding intact non-covalent tetrameric hemoglobin is rather low, due to the denaturing conditions. As expected from the literature, PP succeeds the least in removing interfering protein and showed the most intense band [12]. ILDLLME and SPE showed comparable results. As ILs are known to extract proteins, it was assumed that the IL-DLLME extract would contain a higher portion of serum albumin/hemoglobin compared to SPE. However, this first qualitative assessment does not support the assumption. When comparing band intensities of the IL-DLLME and BSA (1.67 $\mathrm{mg} / \mathrm{mL}$ ) sample, IL-DLLME blood protein removal could be estimated at more than 100-fold, presuming the initial blood sample contained $70 \mathrm{mg} / \mathrm{mL}$ albumin. Furthermore, in IL-DLLME and SPE samples, bands with low intensity were observed at $\pm 15 \mathrm{kDa}$. Most likely, these could be linked to the presence of hemoglobin side chains, e.g. alpha chain $(15.1 \mathrm{kDa})$ or beta chain (15.9 kDa) [20]. Moreover, in the IL-DLLME extract, an additional low-intensity band was detected at $\pm 14 \mathrm{kDa}$. This could be attributed to the presence of beta-2-microglobulin (13.7 $\mathrm{kDa})$, however, this protein is only present at low concentrations in plasma $\left(10^{-7} \mathrm{~g} / \mathrm{mL}\right)[8]$. The low-mass protein "band", found in the PP extract, could be explained by the fact that large proteins are more easily precipitated by organic solvents compared to the smaller ones [21]. 


\subsection{UV/VIS SPECTROPHOTOMETRY}

UV/VIS spectrophotometric results for IL-DLLME, SPE, PP whole blood extracts and 1/20 (v/v) diluted whole blood samples were converted to protein concentrations and displayed in Table 1. The results show that both IL-DLLME and SPE were able to efficiently clean up the whole blood samples, with only 1.18 and $3.03 \mathrm{mg} / \mathrm{mL}$ left of the initial protein concentration, respectively. As could be expected from the SDS-PAGE results, PP is a less successful protein removal technique; almost a third $(19.30 \mathrm{mg} / \mathrm{mL})$ of the initial protein concentration could still be detected in the final extracts. According to the obtained data, the average protein concentration of the undiluted blood samples was estimated at $72.55 \mathrm{mg} / \mathrm{mL}$. This is in line with the average total protein concentrations in blood that were reported by Buzanovskii, i.e. $65-85 \mathrm{mg} / \mathrm{mL}$ [9]. Donor 3 shows slightly higher concentrations, which could be attributed to a possible hemolysis process. Notable are the high relative standard deviation (RSD) values that were seen for SPE and whole blood measurements. This could be caused by the variability in whole blood composition between the three tested donors and the manual operation variability of the SPE extraction. Including a higher number of replicates could also result in improved RSD values. Overall, it was concluded that the IL-DLLME procedure was able to remove a significant portion of blood protein, which resulted in final protein concentrations that were \pm 50 times lower than the initial whole blood sample.

Table 1. NanoDrop UV/VIS spectrophotometry results: protein content of extracts and whole blood

\begin{tabular}{llll|ll}
\hline & \multicolumn{3}{l}{$\begin{array}{l}\text { Protein content }(\mathrm{mg} / \mathrm{mL}) \text { of } \\
\text { whole blood extract }\end{array}$} & & \multicolumn{2}{l}{$\begin{array}{l}\text { Protein content }(\mathrm{mg} / \mathrm{mL}) \text { of } \\
\text { whole blood }\end{array}$} \\
\hline & IL-DLLME & SPE & PP & $\mathbf{1 / 2 0}(\mathbf{v} / \mathbf{v})$ in $\mathbf{H}_{2} \mathbf{O}$ & undiluted \\
\hline Donor 1 & 1.31 & 1.96 & 19.42 & 2.98 & 59.56 \\
Donor 2 & 0.97 & 3.49 & 19.18 & 3.21 & 64.28 \\
Donor 3 & 1.28 & 3.63 & 19.29 & 4.69 & 93.80 \\
\hline Mean $(R S D \%)$ & $\mathbf{1 . 1 8}(16.1)$ & $\mathbf{3 . 0 3}(30.5)$ & $\mathbf{1 9 . 3 0}(6.2)$ & $\mathbf{3 . 6 3}(25.6)$ & $\mathbf{7 2 . 5 5}(25.6)$ \\
\hline
\end{tabular}
precipitation; RSD: relative standard deviation. Three different sources of whole blood were used, indicated by donor 1, donor 2 and donor 3. Undiluted results (highlighted in grey) were calculated from the diluted measurements, by multiplying protein concentrations by 20. RSD: relative standard deviation. 
2 In Table 2, ME results are shown for benzodiazepines in whole blood and water extracts. ME

3 results are similar for both sample sets and do not indicate additional suppression due to whole

4 blood matrix interferences. Multiple $t$-test analysis confirmed that no significant $(\mathrm{p}>0.05)$

5 differences were found between both groups based on the ME results of 28 benzodiazepines.

6 Therefore, the observed ion suppression can be solely attributed to the presence of IL.

7 Especially benzodiazepines that co-elute with the IL peak maximum are most affected, such as

8 7-aminoflunitrazepam (ME: $16 \%$ ), bromazepam (ME: $24 \%$ ) and lorazepam (ME: $39 \%$ ).

9 Furthermore, all CV values were lower than $15 \%$, indicating good repeatability.

Table 2. Matrix effect results of 28 benzodiazepines in IL-DLLME extracts of both whole blood samples and Milli-Q water samples

\begin{tabular}{|c|c|c|c|c|}
\hline Benzodiazepine & $\mathrm{ME}_{\text {Blood }}(\%)$ & $\mathrm{CV}(\%)$ & $\mathrm{ME}_{\mathrm{H} 2 \mathrm{O}}(\%)$ & $\mathrm{CV}(\%)$ \\
\hline 7-Aminoflunitrazepam & 16.3 & 9.7 & 16.4 & 3.5 \\
\hline Alprazolam & 52.6 & 2.1 & 52.5 & 6.4 \\
\hline Bromazepam & 24.1 & 5.9 & 24.5 & 14.2 \\
\hline Brotizolam & 54.5 & 6.2 & 52.4 & 7.4 \\
\hline Chlordiazepoxide & 52.0 & 7.4 & 49.6 & 7.2 \\
\hline Clobazam & 53.2 & 3.2 & 52.2 & 5.9 \\
\hline Clonazepam & 47.6 & 6.3 & 47.2 & 7.1 \\
\hline Clorazepate & 46.5 & 5.5 & 44.1 & 6.2 \\
\hline Clotiazepam & 56.6 & 1.1 & 54.0 & 2.6 \\
\hline Cloxazolam & 48.5 & 7.4 & 46.7 & 10.3 \\
\hline Diazepam & 57.8 & 6.4 & 54.0 & 5.4 \\
\hline Estazolam & 51.8 & 3.6 & 51.5 & 0.5 \\
\hline Etizolam & 57.7 & 3.3 & 53.6 & 3.1 \\
\hline Ethyl loflazepate & 58.7 & 11.5 & 55.9 & 9.2 \\
\hline Flunitrazepam & 58.7 & 6.4 & 59.2 & 7.0 \\
\hline Flurazepam & 63.3 & 1.8 & 60.6 & 1.2 \\
\hline Loprazolam & 73.3 & 4.8 & 67.1 & 5.1 \\
\hline Lorazepam & 39.5 & 4.2 & 38.3 & 5.8 \\
\hline Lormetazepam & 48.3 & 9.9 & 47.8 & 8.8 \\
\hline Midazolam & 56.7 & 8.4 & 54.1 & 5.7 \\
\hline Nitrazepam & 37.8 & 4.6 & 37.4 & 7.8 \\
\hline Nordiazepam & 51.3 & 8.3 & 51.3 & 8.5 \\
\hline Oxazepam & 36.6 & 11.1 & 37.9 & 4.7 \\
\hline Prazepam & 56.1 & 3.9 & 53.6 & 4.0 \\
\hline Temazepam & 53.1 & 1.4 & 52.3 & 3.2 \\
\hline Triazolam & 47.5 & 1.6 & 44.4 & 4.7 \\
\hline Zolpidem & 56.2 & 4.6 & 55.8 & 5.9 \\
\hline Zopiclone & 52.2 & 4.5 & 57.2 & 8.9 \\
\hline
\end{tabular}

ME Blood: matrix effect of whole blood extracted using ionic liquid-based liquid-liquid microextraction (ILDLLME); ME н20: matrix effect of Milli-Q water extracted using IL-DLLME; CV: coefficient of variation ( $\mathrm{n}=$ 


\section{CONCLUSION}

The obtained SDS-PAGE results showed that serum albumin and/or hemoglobin were extracted from whole blood and could be detected as a small band at $65 \mathrm{kDa}$ in the IL-DLLME extract. A protein band with comparable intensity was found in the final SPE extract. The PP extract showed a more prominent band, indicating less efficient protein removal. UV/VIS spectrophotometric tests confirmed the SDS-PAGE results; both IL-DLLME and SPE protocols were able to remove more than $95 \%$ of the sample protein content, however, IL-DLLME has proven to be more time efficient and consumes less volatile organic solvents. The most straightforward technique, PP, did only succeed in removing $\pm 75 \%$ of the total protein content. Nevertheless, it should be mentioned that the applied PP protocol used a 2:1 (ACN:sample) ratio, while a study by Polson et al. has proven that protein removal could be further maximized by using 3:1 or 4/1 ratios [11]. Finally, the obtained ME results for 28 benzodiazepines showed no significant differences between whole blood and water IL-DLLME extracts. This means that endogenous substances, such as proteins, did not have a significant influence on benzodiazepine ionization. The observed ion suppression could therefore be attributed to the presence of IL. This is probably the biggest disadvantage of IL-DLLME, fortunately, the IL matrix effect has proven to be repeatable $(\mathrm{CV}<15 \%)$ and can be considered in the process of establishing calibration curves.

Overall, the performed tests demonstrate the efficient matrix removal capacity of the tested IL, i.e. $\mathrm{BMIm} \mathrm{PF}_{6}$. Most ILs that are used for the extraction of small molecules are hydrophobic solvents and therefore have a weak tendency to dissolve proteins. This is a desirable property for an extraction solvent in biological sample clean-up. Care should be taken if hydrophilic ILs are used in aqueous two-phase systems for drug extraction, as $\mathrm{BMIm} \mathrm{Cl} / \mathrm{K}_{2} \mathrm{HPO}_{4}$ systems have been described to also extract proteins form biological samples [5].

\section{ACKNOWLEDGEMENTS}

The authors want to thank Nele Pierre for the help with the performance of the NanoDrop experiments. 
The authors declare no conflicts of interest. This research did not receive any specific grant from funding agencies in the public, commercial, or not-for-profit sectors.

\section{REFERENCES}

[1] M. Vian, C. Breil, L. Vernes, E. Chaabani, F. Chemat, Green solvents for sample preparation in analytical chemistry, Curr. Opin. Green Sustain. Chem. 5 (2017) 44-48. doi:10.1016/j.cogsc.2017.03.010.

[2] F. Pena-Pereira, J. Namiesnik, Ionic liquids and deep eutectic mixtures: Sustainable solvents for extraction processes, ChemSusChem. 7 (2014) 1784-1800. doi:10.1002/cssc.201301192.

[3] J.H. Davis, Task-Specific Ionic Liquids, Chem. Lett. 33 (2004) 1072-1077. doi:10.1246/cl.2004.1072.

[4] K.D. Clark, M.N. Emaus, M. Varona, A.N. Bowers, J.L. Anderson, Ionic liquids: solvents and sorbents in sample preparation, J. Sep. Sci. 41 (2018) 209-235. doi:10.1002/jssc.201700864.

[5] S. Dreyer, P. Salim, U. Kragl, Driving forces of protein partitioning in an ionic liquid-based aqueous two-phase system, Biochem. Eng. J. 46 (2009) 176-185. doi:10.1016/j.bej.2009.05.005.

[6] R.J. Dinis-Oliveira, D.N. Vieira, T. Magalhães, Guidelines for Collection of Biological Samples for Clinical and Forensic Toxicological Analysis, Forensic Sci. Res. 1 (2016) 42-51. doi:10.1080/20961790.2016.1271098.

[7] R. Verplaetse, J. Tytgat, Liquid chromatography tandem mass spectrometry in forensic toxicology: what about matrix effects?, TIAFT Bull. 41 (2011) 8-16. https://lirias.kuleuven.be/bitstream/123456789/402675/1/Tiaft_Bulletin_2011_RuthVerplaetse. pdf (accessed December 28, 2017).

[8] S. Schenk, G.J. Schoenhals, G. de Souza, M. Mann, A high confidence, manually validated human blood plasma protein reference set, BMC Med. Genomics. 1 (2008) 41. doi:10.1186/1755-8794-1-41.

[9] V.A. Buzanovskii, Determination of proteins in blood. Part 1: Determination of total protein and albumin, Rev. J. Chem. 7 (2017) 79-124. doi:10.1134/S2079978017010010.

[10] J.M. Otto, J.O.M. Plumb, E. Clissold, S.B. Kumar, D.J. Wakeham, W. Schmidt, M.P.W. Grocott, T. Richards, H.E. Montgomery, Hemoglobin concentration, total hemoglobin mass and plasma volume in patients: Implications for anemia, Haematologica. 102 (2017) 1477-1485. doi:10.3324/haematol.2017.169680.

[11] C. Polson, P. Sarkar, B. Incledon, V. Raguvaran, R. Grant, Optimization of protein precipitation based upon effectiveness of protein removal and ionization effect in liquid chromatographytandem mass spectrometry, J. Chromatogr. B. 785 (2003) 263-275. doi:10.1016/S15700232(02)00914-5.

[12] L. Patteet, D. Cappelle, K.E. Maudens, C.L. Crunelle, B. Sabbe, H. Neels, Advances in detection of antipsychotics in biological matrices, Clin Chim Acta. 441C (2014) 11-22. doi:10.1016/j.cca.2014.12.008.

[13] S.M.R. Wille, W.E.E. Lambert, Recent developments in extraction procedures relevant to 
analytical toxicology, Anal Bioanal Chem. 388 (2007) 1381-1391. doi:10.1007/s00216-0071294-z.

[14] R.A. Chen, X.H., Franke, J.P., Wijsbeek, J., de Zeeuw, Isolation of Acidic, Neutral, and Basic Drugs from Whole Blood Using A Single Mixed-Mode Solid-Phase Extraction Column, J. Anal. Toxicol. 16 (1992) 351-5. http://www.ncbi.nlm.nih.gov/pubmed/1293399 (accessed January 22, 2018).

[15] F.R. Mansour, M.A. Khairy, Pharmaceutical and biomedical applications of dispersive liquidliquid microextraction, J. Chromatogr. B. 1061-1062 (2017) 382-391. doi:10.1016/j.jchromb.2017.07.055.

[16] J.J. Wang, Y.C. Pei, Y. Zhao, Z.G. Hu, Recovery of amino acids by imidazolium based ionic liquids from aqueous media, Green Chem. 7 (2005) 196-202. doi:10.1039/b415842c.

[17] R. Verplaetse, E. Cuypers, J. Tytgat, The evaluation of the applicability of a high $\mathrm{pH}$ mobile phase in ultrahigh performance liquid chromatography tandem mass spectrometry analysis of benzodiazepines and benzodiazepine-like hypnotics in urine and blood, J. Chromatogr. A. 1249 (2012) 147-154. doi:10.1016/j.chroma.2012.06.023.

[18] M. De Boeck, S. Missotten, W. Dehaen, J. Tytgat, E. Cuypers, Development and validation of a fast ionic liquid-based dispersive liquid-liquid microextraction procedure combined with LCMS/MS analysis for the quantification of benzodiazepines and benzodiazepine-like hypnotics in whole blood, Forensic Sci Int. 274 (2017) 44-54. doi:10.1016/j.forsciint.2016.12.026.

[19] B.K. Matuszewski, M.L. Constanzer, C.M. Chavez-Eng, B.K.. C. Matuszewski M.L.; ChavezEng, C.M., Strategies for the assessment of matrix effect in quantitative bioanalytical methods based on HPLC-MS/MS., Anal. Chem. 75 (2003) 3019-3030. doi:10.1021/ac020361s.

[20] R.J. Hill, W. Konigsberg, G. Guidotti, L.C. Craig, The structure of human hemoglobin. I. The separation of the alpha and beta chains and their amino acid composition., J. Biol. Chem. 237 (1962) 1549-1554. http://www.ncbi.nlm.nih.gov/pubmed/13907376 (accessed May 30, 2018).

[21] I.M. Rosenberg, Getting started with protein purification, in: Protein Anal. Purif. Benchtop Tech., Birkhauser, Boston, 1996: pp. 118-152.

\section{FIGURE CAPTIONS}

Figure 1.

\section{SDS-PAGE results of IL-DLLME, SPE and PP whole blood extracts.}

Lane 1: PageRuler low range unstained protein ladder; Lane 2: solid-phase extraction (SPE) of whole blood sample; Lane 3: protein precipitation (PP) of whole blood sample; Lane 4: ionic liquid-based dispersive liquid-liquid microextraction (IL-DLLME) of whole blood sample; Lane 5: bovine serum albumin positive control $(1.67 \mathrm{mg} / \mathrm{mL})$; Lane 6: PageRuler low range unstained protein ladder. 